\title{
ZIP8 exacerbates collagen-induced arthritis by increasing pathogenic $T$ cell responses
}

\author{
Jung-Ah Kang 1,2,3, Ji-Sun Kwak ${ }^{1,4}$, Sang-Heon Park ${ }^{1,2,5}$, Kyu-Young Sim ${ }^{1,2,5}$, Seul Ki Kim,4, Youngnim Shin ${ }^{1,4}$, \\ In Jung Jung ${ }^{1,4}$, Jeong-In Yang ${ }^{1,4}$, Jang-Soo Chun ${ }^{1,2,4}$ and Sung-Gyoo Park $\mathbb{B}^{1,2,5}$
}

\begin{abstract}
Zinc is a trace element that is essential for immune responses. Therefore, changes in cellular zinc levels in specific immune cells may influence inflammatory autoimmune diseases, such as rheumatoid arthritis (RA). However, the regulation of zinc mobilization in immune cells and its role in the pathogenesis of RA are not fully understood. Thus, we investigated the roles of zinc transporters in RA pathogenesis. We demonstrated that ZIP8 was specifically upregulated in $\mathrm{CD}^{+} \mathrm{T}$ cells that infiltrated the inflamed joint and that ZIP8 deficiency in $\mathrm{CD}^{+} \mathrm{T}$ cells abrogated collagen-induced arthritis. ZIP8 deficiency dramatically affected zinc influx in effector T cells and profoundly reduced T cell receptor (TCR)-mediated signaling, including NF-KB and MAPK signaling, which are pathways that are involved in T helper (Th) 17 cell differentiation. Taken together, our findings suggest that ZIP8 depletion in CD4 ${ }^{+} \mathrm{T}$ cells attenuates TCR signaling due to insufficient cellular zinc, thereby reducing the function of effector CD4 ${ }^{+} \mathrm{T}$ cells, including Th17 cells. Our results also suggest that targeting ZIP8 may be a useful strategy to inhibit RA development and pathogenesis.
\end{abstract}

\section{Introduction}

Rheumatoid arthritis (RA) is a chronic inflammatory autoimmune disease that primarily affects joint tissues. This disease is characterized by synovial inflammation, cartilage destruction, and bone erosion ${ }^{1,2}$. The molecular mechanisms of RA pathogenesis are not fully understood, but the onset and progression of RA are known to be associated with various genetic factors. For example, the human leukocyte antigen allele $H L A-D R B 1$ in the major histocompatibility locus was the first RA risk locus identified; this allele regulates disease progression by affecting the $\mathrm{T}$ cell receptor (TCR) repertoire and/or the presentation of antigens to self-reactive $\mathrm{T}$ cells ${ }^{3,4}$. Alleles of

\footnotetext{
Correspondence: Jang-Soo Chun (jschun@gist.ac.kr)

Sung-Gyoo Park (riceo2@snu.ac.kr)

'School of Life Sciences, Gwangju Institute of Science and Technology, Gwangju 61005, Republic of Korea

${ }^{2}$ Cell Logistics Research Center, Gwangju Institute of Science and Technology, Gwangju 61005, Republic of Korea

Full list of author information is available at the end of the article

These authors contributed equally: Jung-Ah Kang, Ji-Sun Kwak,
}

Sang-Heon Park other genes, such as CD28, TRAF1, PTPN22, and CTLA-4 are also known to increase the risk of RA development. These RA-associated alleles are related to immune cell functions, and many are associated with the regulation of $\mathrm{T}$ cell responses ${ }^{3,4}$.

During synovial inflammation in RA pathogenesis, various leukocytes infiltrate the synovial compartment via the increased expression of adhesion molecules and chemokines in the endothelium, leading to the production of large amounts of chemokines and proinflammatory cytokines in inflamed synovial tissues ${ }^{2}$. Among the infiltrating cells, $\mathrm{CD} 4^{+} \mathrm{T}$ cells are necessary for RA onset ${ }^{5,6}$, and $\mathrm{CD} 4^{+} \mathrm{T}$ cell depletion suppresses autoantibody production and reduces the disease severity of collagen- or antigen-induced arthritis in rodent models ${ }^{6,7}$. Moreover, therapeutic strategies to block $\mathrm{T}$ cell costimulation are very effective against both the early and advanced disease stages of $\mathrm{RA}^{8,9} \cdot \mathrm{CD}^{+} \mathrm{T}$ cells and macrophages are the main cell types that infiltrate the RA synovium ${ }^{5,6}$. Subsequent to the discovery of interleukin (IL)-17-producing $\mathrm{CD}^{+}{ }^{+} \mathrm{T}$ cells in the RA synovium, studies using animal 
models have revealed that $\mathrm{T}$ helper (Th)17 cells are key players in various autoimmune and inflammatory diseases $^{10,11}$. In addition to the critical involvement of Th17 cells, RA has been considered to be a Th1-dependent disease. However, experimental deficiency of Th1promoting cytokines, such as IL-12 and interferon (IFN)- $\gamma$, has been shown to increase Th17 cell differentiation and paradoxically exacerbate RA in animal models $^{12}$.

Zinc is a trace element that is essential for life, and organisms have evolved processes to strictly maintain zinc homeostasis ${ }^{13}$. In mammalian cells, zinc homeostasis is primarily regulated by membrane zinc transporters in the Slc30a (ZNT) exporter family and the Slc39a (ZIP) importer family ${ }^{14}$. The ZNT family, which consists of ten members in mammals (ZNT1-ZNT10), mediates the efflux of zinc from cells or the influx of zinc from the cytosol to intracellular vesicles. In contrast, the 14 members of the ZIP family in mammals (ZIP1-ZIP14) promote the influx of zinc from the extracellular space or intracellular vesicles into the cytoplasm. Previous reports have indicated that serum zinc levels are significantly lower in RA patients than in healthy controls ${ }^{15,16}$. In addition, zinc has been suggested to be an anti-inflammatory element ${ }^{17}$. In the immune system, zinc deficiency induces thymic atrophy and lymphopenia and reduces immune responses by regulating the functions of various immune cells, including macrophages, neutrophils, natural killer cells, B cells, and $\mathrm{T}$ cells ${ }^{18}$. Previous reports have indicated that ZIP8-mediated zinc import negatively regulates macrophage activation ${ }^{19}$, whereas ZIP10-mediated zinc import positively affects macrophage-mediated immune respon$\mathrm{ses}^{20}$. In addition, it has been reported that ZIP9 and ZIP10 are crucial for B cell receptor signaling cascades and affect $B$ cell activation ${ }^{21,22}$. In T cells, ZIP6 affects TCR signaling cascades ${ }^{23}$, and ZIP8 is involved in cytokine production by activated $\mathrm{T}$ cells ${ }^{24}$. In summary, these reports delineate the specific roles of individual zinc transporters in regulating immune cell functions. Additionally, proinflammatory cytokines have been shown to alter the expression levels of zinc transporters, thereby decreasing serum zinc levels ${ }^{25}$.

Here, we investigated the possible role of specific zinc transporter-mediated zinc mobilization in RA pathogenesis. In the present study, we analyzed the expression levels and functions of ZIP and ZNT family members in T and $B$ cells and macrophages. We found that the zinc transporter ZIP8 was specifically upregulated in inflamed synovial cells. Among the immune cells that infiltrated the inflamed joint tissues, we observed that synovial but not peripheral $\mathrm{CD}_{4}^{+} \mathrm{T}$ cells highly expressed ZIP8 on the cell surface. We further characterized the role of ZIP8 in $\mathrm{CD}^{+} \mathrm{T}$ cell functions and found that ZIP8 was crucial for regulating the functions of infiltrating $\mathrm{CD}^{+} \mathrm{T}$ cells during the onset and progression of collagen-induced arthritis (CIA).

\section{Materials and methods \\ Mice and $\mathrm{CIA}$}

Slc39a8 ${ }^{+/-}, \mathrm{Mtf1}^{+/-}$, and $\mathrm{Mt1^{-/- }} \mathrm{Mt2^{-/- }}$ mice were created as described previously ${ }^{26,27}$. Slc39a $8^{\mathrm{f} / \mathrm{f}}$ mice were crossed with Lysm-Cre or CD4-Cre Tg mice (The Jackson Laboratory) to generate macrophage- or CD4 $\mathrm{T}$ cellspecific conditional knockout (cKO) mice $\left(\operatorname{Slc} 39 a 8^{\mathrm{f} / \mathrm{f}}\right.$; Lysm-Cre and Slc39a ${ }^{\mathrm{f} / \mathrm{f}}$;CD4-Cre mice, respectively) on a C57BL/6 background. Each mouse line was backcrossed with DBA/1 J mice to generate the corresponding mice on a DBA/1 J background. All mice were maintained under pathogen-free conditions and used in accordance with protocols approved by the Animal Care and Ethics Committees of the Gwangju Institute of Science and Technology. CIA was induced according to a standard protocol $^{28}$. Cumulative CIA incidence (score 1) was evaluated on the indicated days after the first immunization. All other CIA parameters were evaluated after the mice were sacrificed on day 36 or 39 after the first immunization. CIA severity was evaluated using a clinical score (grade 0-4) of paw swelling. Joint tissues were fixed, decalcified with 0.5 M EDTA, embedded in paraffin, and sectioned at a thickness of $5 \mu \mathrm{m}$. Synovitis was evaluated by Safranin-O and hematoxylin staining, and synovial inflammation (grade 0-4) was scored as previously described $^{28}$. The pannus was visualized by H\&E staining and quantified by scoring (grade $0-4)^{28,29}$. Cartilage destruction was visualized by Safranin-O staining and quantified by scoring cartilage extracellular matrix loss (score 0: normal; 1: slight reduction; 2: moderate reduction; 3: severe reduction; and 4: absent).

\section{Immunohistochemistry and immunofluorescence microscopy}

Mouse joint tissues were sectioned at a thickness of $5 \mu \mathrm{m}$ for immunohistochemical staining. Antigens were retrieved by incubating the joint sections at $60^{\circ} \mathrm{C}$ overnight with sodium citrate buffer $(10 \mathrm{mM}$ sodium citrate, $0.05 \%$ Tween $20, \mathrm{pH}$ 6.0). The sections were blocked with $1 \%$ bovine serum albumin in phosphate-buffered saline (PBS) and then incubated with primary antibodies, including rabbit antiZIP8 (Santa Cruz), rabbit anti-metal-regulatory transcription factor-1 (MTF1), anti-metallothionein 1 (MT1)/MT2 (Novus Biologicals), rabbit anti-matrix metalloproteinase 3 (MMP3), anti-receptor activator of NF-kB ligand (RANKL), and anti-Ki67 (Abcam). The Dako REAL Envision detection system was used for chromogenic color development. Tartrate-resistant acid phosphatase (TRAP)-positive osteoclasts were examined using a TRAP kit (Sigma-Aldrich) and counted in regions containing pannus-cartilage and pannus-bone interfaces ${ }^{29}$. ZIP8-expressing cells in the 
synovial tissues of CIA mice or primary cultures of total synovial cells isolated from CIA mice were identified by double immunofluorescence labeling with vimentin for fibroblast-like synoviocytes (FLSs), CD11b for macrophages, $\mathrm{CD} 4$ for $\mathrm{T}$ cells, and B220 for B cells. The following primary antibodies were used: mouse anti-CD4 (Abcam), rat antiB220 (eBioscience), rat anti-CD11b (Abcam), rabbit antiZIP8 (Santa Cruz), and mouse anti-vimentin (BD Pharmingen). Blood vessels in synovial tissues were detected with rat anti-CD31 antibodies (Dianova). ZIP8 in isolated $\mathrm{CD}_{4}^{+} \mathrm{T}$ cells was analyzed by immunofluorescence microscopy using rabbit anti-ZIP8 antibodies (Alomone Labs).

\section{Isolation and analysis of total synovial cells}

Total synovial cells were isolated from the knee joints of nonimmunized (NI) or CIA mice ${ }^{29}$. Synovial tissues were minced and digested in collagenase (Worthington, $2 \mathrm{mg} /$ $\mathrm{mL}$ ) for $4 \mathrm{~h}$ at $37^{\circ} \mathrm{C}$. Total cells were subjected to mRNA extraction for qRT-PCR analysis, primary culture to identify ZIP8-expressing cells (described above), and flow cytometric analysis to identify ZIP8-expressing infiltrated cells (described below).

\section{Zinc assays}

Synovial fluid was collected from both knees of NI and CIA mice by joint aspiration ${ }^{30}$. The collected fluid was measured by the 'pipette-dialing' technique ${ }^{30}$. The volume collected was not significantly different between $\mathrm{NI}$ and CIA mice. The collected synovial fluid was mixed with $100 \mu \mathrm{l}$ of PBS, and samples were cleared by centrifugation at $15,000 \mathrm{~g}$ for $20 \mathrm{~min}$. The levels of zinc were determined by using a zinc quantification kit (Abcam) according to the manufacturer's instructions. To assess zinc influx in isolated primary naive (CD62L $\left.{ }^{\text {high }} \mathrm{CD} 44^{\text {low }}\right) \mathrm{CD} 4^{+} \mathrm{T}$ (Tnaive) cells and effector memory $\left(\mathrm{CD} 62 \mathrm{~L}^{\text {low }} \mathrm{CD} 44^{\text {high }}\right) \mathrm{CD} 4^{+} \mathrm{T}$ (Tem) cells, the cells were incubated with $1 \mu \mathrm{g} / \mathrm{mL}$ Fluo- 4 AM (cell permeant, Thermo) in PBS at $37^{\circ} \mathrm{C}$. After being washed with PBS, the cells were resuspended in PBS containing $45 \mu \mathrm{M} \mathrm{ZnCl} 2$. The intensity of the cellular dye was measured using a fluorescent plate reader (Molecular Devices) every $5 \mathrm{~s}$ for a total of $65 \mathrm{~s}$. Intracellular zinc was measured using the probe ZnAF-1F (Santa Cruz). The sections of cartilage tissues were treated with $10 \mu \mathrm{M}$ probe for $60 \mathrm{~min}$ at $37^{\circ} \mathrm{C}$. The sections were then washed with PBS, and zinc distribution images were acquired with a fluorescence microscope ${ }^{26}$.

\section{Enzyme-linked immunosorbent assay (ELISA) analysis of autoantibody production}

Type II collagen-specific antibodies were measured by ELISA (Immunology Consultants Lab) according to the manufacturer's instructions ${ }^{29}$.

\section{Flow cytometry}

Thymocytes, splenocytes, and lymphocytes were isolated from Slc39a8 $8^{f / f}$ and Slc39af ${ }^{f / f} ; C D 4-C r e$ mice as previously described ${ }^{29}$. The following antibodies were purchased from eBioscience for cell staining: Alexa Fluor 488-conjugated anti-mouse CD4 (GK1.5), fluorescein isothiocyanate (FITC)-conjugated anti-mouse TCR $\beta$ (H57-597), FITC-conjugated anti-mouse CD8 (53-6.7), peridinin chlorophyll protein cyanine 5.5 (PerCP Cy5.5)conjugated anti-mouse CD25 (PC61.5), allophycocyanin (APC)-conjugated anti-mouse CD4 (GK1.5), APCconjugated anti-mouse B220 (RA3-6B2), APCconjugated anti-mouse IL-17A (eBio17B7), PerCP Cy5.5-conjugated anti-mouse CD62L (MEL-14), PerCP Cy5.5-conjugated anti-mouse IFN- $\gamma$ (XMG1.2), and phycoerythrin-conjugated anti-human/mouse CD44 (IM7). Live cells were stained for $1 \mathrm{~h}$ at $4{ }^{\circ} \mathrm{C}$ and then fixed in $2.5 \%$ (wt/vol.) paraformaldehyde. To analyze activated $\mathrm{CD}^{+} \mathrm{T}$ cells from Slc39a8 ${ }^{f / f}$ and Slc39a8 ${ }^{f / f} ;$ CD4-Cre mice, the cells were activated for the indicated times with $5 \mu \mathrm{g} / \mathrm{mL}$ of anti-mouse CD3 (17A2) and anti-mouse CD28 (145-2C11) antibodies (both from Bio X Cell), after which the cells were stained with the indicated antibodies. For intracellular cytokine staining, isolated splenic cells or lymph node cells were stimulated for $6 \mathrm{~h}$ with phorbol myristate acetate $(50 \mathrm{ng} / \mathrm{mL})$ and ionomycin $(500 \mathrm{ng} / \mathrm{mL}$ ) in the presence of GolgiPlug (BD Pharmingen $)^{29}$. Data were collected using a FACSCanto II (BD Biosciences) and analyzed with FlowJo software (BD Biosciences).

\section{In vitro differentiation of Th17 cells}

$\mathrm{CD}^{+} \mathrm{T}$ cells were isolated from the spleens of Slc39a $8^{f / f}$ and Slc39a ${ }^{f / f} ; C D 4-C r e$ mice using an EasySep ${ }^{\mathrm{TM}}$ Mouse $\mathrm{CD}^{+} \mathrm{T}$ cell Isolation Kit (Stem Cell). For in vitro differentiation of $\mathrm{CD}^{+} \mathrm{T}$ cells into Th1 cells, isolated cells $\left(2 \times 10^{5}\right)$ were cultured with anti-mouse CD3 antibodies $(5 \mu \mathrm{g} / \mathrm{mL})$, anti-mouse CD28 antibodies $(5 \mu \mathrm{g} / \mathrm{mL}), \mathrm{IL}-12$ $(20 \mathrm{ng} / \mathrm{mL}), \mathrm{IL}-2(20 \mathrm{ng} / \mathrm{mL})$, and anti-IL-4 antibodies $(10 \mu \mathrm{g} / \mathrm{mL})$. For in vitro differentiation of $\mathrm{CD} 4^{+} \mathrm{T}$ cells into Th17 cells, isolated cells $\left(2.5 \times 10^{5}\right)$ were cultured with anti-mouse CD3 $(5 \mu \mathrm{g} / \mathrm{mL})$ and anti-mouse CD28 $(5 \mu \mathrm{g} / \mathrm{mL})$ antibodies, IL- $6(100 \mathrm{ng} / \mathrm{mL})$, TGF- $\beta(5 \mathrm{ng} / \mathrm{mL})$, and anti-IFN- $\gamma(10 \mu \mathrm{g} / \mathrm{mL})$ and anti-IL- $4(10 \mu \mathrm{g} / \mathrm{mL})$ antibodies. IFN- $\gamma$ - or IL-17A-producing cells were evaluated by flow cytometry ${ }^{29}$.

\section{Cytokine analysis}

$\mathrm{CD} 4^{+} \mathrm{T}$ cells were isolated from $S l c 39 a 8^{\mathrm{f} / \mathrm{f}}$ and $S l c 39 a 8^{\mathrm{f} / \mathrm{f}}$; CD4-Cre mice on day 39 after the first immunization. To determine protein levels, the BD Cytometric Bead Array, mouse Th1/Th2/Th17 Cytokine Kit (BD Biosciences), and a FACSCanto II flow cytometer (BD Biosciences) were used to measure the secreted cytokines IL-2, IL-6, IL-10, 
IL-17A, IFN- $\gamma$, and tumor necrosis factor (TNF)- $\alpha$. The mRNA levels of the indicated cytokines were determined by quantitative RT-PCR (described below).

\section{Proliferation assay}

Tnaive and Tem cells $\left(5 \times 10^{4}\right)$ isolated from Slc39a $8^{\mathrm{f} / \mathrm{f}}$ and $S l c 39 a 8^{\mathrm{f} / \mathrm{f}} ; C D 4-C r e$ mice were stimulated with antimouse CD3 $(5 \mu \mathrm{g} / \mathrm{mL})$ and anti-mouse CD28 $(5 \mu \mathrm{g} / \mathrm{mL})$ antibodies for $72 \mathrm{~h}$. At $60 \mathrm{~h}$ after activation, $\left[{ }^{3} \mathrm{H}\right]$ thymidine was added to measure Tnaive and Tem cell proliferation. After $12 \mathrm{~h}$, the incorporation of $\left[{ }^{3} \mathrm{H}\right]$ thymidine into the nuclear DNA of activated Tnaive and Tem cells was measured. Tnaive and Tem cells were also stained with $5 \mu \mathrm{M}$ CellTrace Violet (CTV) (Thermo) for $5 \mathrm{~min}$, and labeling was stopped by the addition of RPMI 1640 medium (HyClone) supplemented with 10\% fetal bovine serum (HyClone). After several washes, the CTV-labeled cells were incubated for 48-72 h. Data were collected using a FACSCanto II (BD Biosciences) and analyzed with FlowJo software.

\section{Quantitative RT-PCR and western blot analysis}

The PCR primers used and experimental conditions were described previously for ZIP and ZNT family members $^{26}$ and various cytokines ${ }^{29}$. Transcript levels were determined by quantitative qRT-PCR. The following antibodies were used for western blotting: rabbit antiZIP6 (Thermo), rabbit anti-ZIP8 (Santa Cruz), mouse anti-GAPDH (Santa Cruz), mouse anti-lymphocytespecific protein tyrosine kinase (LCK) (Santa Cruz), mouse anti-CD4 (Santa Cruz), mouse anti-phospho-TCR $\zeta$ (Thermo), rabbit anti-src homology 2 domain-containing protein tyrosine phosphatase 1 (Shp-1) (Cell Signaling), rabbit anti-phospho-extracellular signal-regulated kinase (ERK) (Cell Signaling), anti-phospho-c-Jun N-terminal kinase (JNK) (Cell Signaling), mouse anti-inhibitor of $\kappa B \alpha$ $(\mathrm{I} \kappa \mathrm{B} \alpha)$ (Santa Cruz), mouse anti-phospho-IкB $\alpha$ (Cell Signaling), rabbit anti-protein kinase B (AKT) (Cell Signaling), and rabbit anti-phospho-AKT (Cell Signaling).

\section{Microarray analysis}

Gene expression data were obtained from the study by Woetzel et al. $^{31}$, as deposited in the Gene Expression Omnibus DataSets database at the National Center for Biotechnology Information (NCBI) (http://www.ncbi.nlm. nih.gov/gds/). The data can be found at accession numbers [GDS5401] ('Berlin' data), GDS5402 ('Leipzig' data), and GDS5403 ('Jena' data).

\section{Statistical analysis}

For statistical comparisons of experimental groups, the datasets were examined by the Shapiro-Wilk test for normality and Levene's test for homogeneity of variance. Nonparametric data based on the ordinal grading of mouse experimental groups (i.e., clinical score, synovitis, pannus formation, and OARSI grade) were compared using the Mann-Whitney $U$ test. Parametric data collected from two independent experimental groups were evaluated by a two-tailed $t$-test. For comparisons of three or more groups, one-way analysis of variance (ANOVA) with a post hoc Bonferroni test was used. For the incidence of CIA, the chi-square $\left(\chi^{2}\right)$ test was used. Each $N$ number indicates the number of biologically independent samples or the number of mice per group. Significance was accepted at a probability level of $0.05(P<0.05)$. The bars represent the SEM or SD for parametric data and the calculated $95 \%$ confidence interval $(95 \%$ CI $)$ for nonparametric data.

\section{Results}

\section{ZIP8 is specifically upregulated in the inflamed joint tissues of CIA mice and human RA patients}

The serum zinc levels of RA patients are significantly lower than those of healthy individuals ${ }^{15,16}$. We also found significantly lower serum zinc levels in CIA mice than in NI control mice (Fig. 1a). However, CIA mice exhibited significantly increased zinc levels in synovial fluid (Fig. 1b) and synovial tissues (Fig. 1c) compared with those of control mice. This result indicates an alternation in zinc homeostasis under CIA conditions. To investigate the possible mechanisms of zinc mobilization into the inflamed joint tissues of CIA mice, we analyzed the mRNA levels of all ZIP and ZNT family members in total synovial cells. We observed specific upregulation of ZIP8 (Fig. 1d). Consistent with this finding, the ZIP8 protein level was markedly increased in the CIA synovium, in which the RA synovial marker MMP3 was detected (Fig. 1e). We additionally found upregulation of the zincdependent transcription factor MTF1 and the MTF1 target protein $\mathrm{MTs}^{32}$ in the CIA synovium (Fig. 1e). Analysis of gene expression microarray datasets ${ }^{31}$ from the Gene Expression Omnibus database (Fig. 1f) revealed that ZIP8 mRNA was also significantly upregulated in the synovial tissues of RA patients.

\section{ZIP8 regulates $\mathrm{CIA}$ in mice}

Next, we investigated the potential role of the zinc-ZIP8-MTF1-MT axis in the pathogenesis of CIA using mice engineered with haplodeficiency of ZIP8 $\left(\operatorname{Slc} 39 a 8^{+/-}\right)$or MTF1 $\left(M t f 1^{+/-}\right)$, or double deficiency of MT1 and MT2 $\left(M t 1^{-l-} M t 2^{-/-}\right)^{26}$. We used heterozygous Slc39a $8^{+-}$and $M t f 1^{+/-}$mice because homozygous deletion of Slc39a8 or Mtf1 is embryonic lethal ${ }^{33,34}$, and we used $M t 1$ and $M t 2$ double-knockout (KO) mice 26,32 $^{2}$ because MT1 and MT2 may have redundant properties, being almost identical in their structures and functions ${ }^{32}$. Compared with wild-type (WT) littermates, Slc39a $8^{+/-}$ mice exhibited profound inhibition of CIA incidence, and 

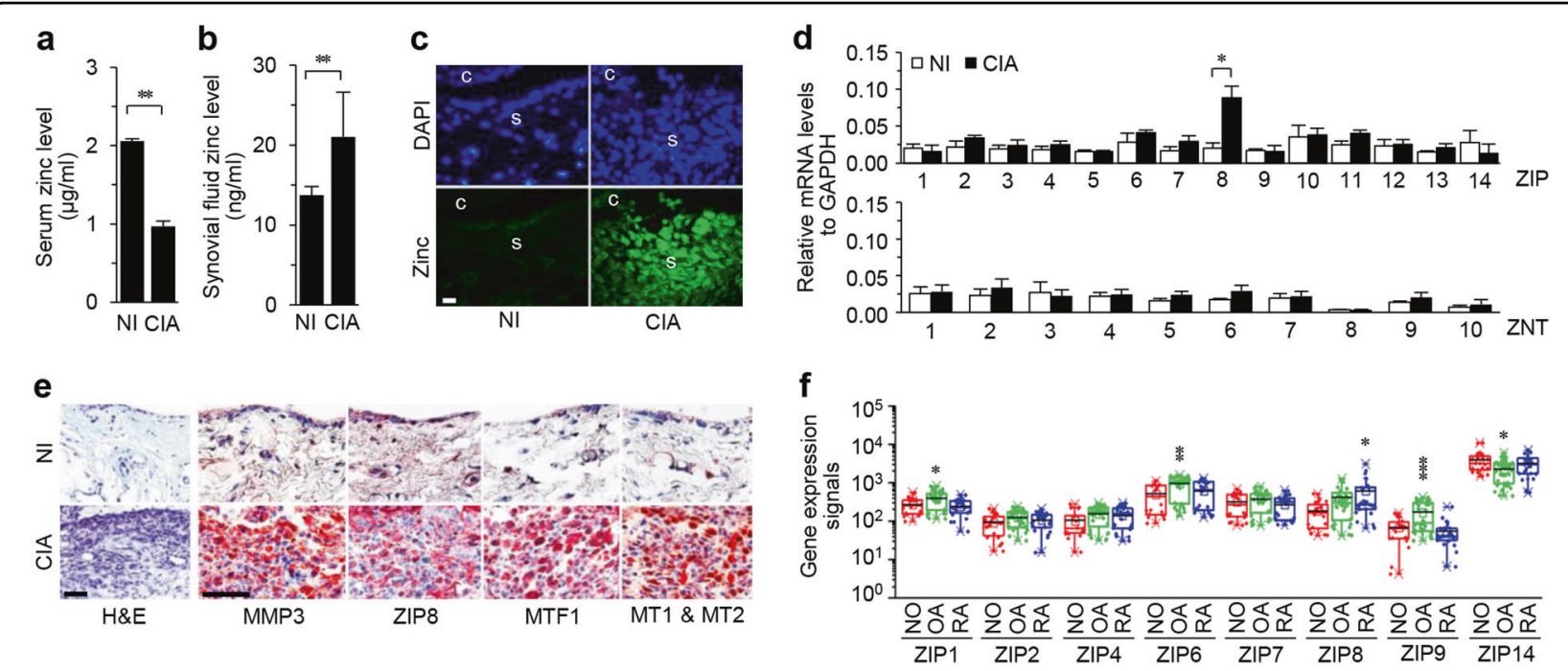

Fig. 1 ZIP8 is upregulated in the inflamed joint tissues of CIA mice and RA patients. a, $\mathbf{b}$ Zinc levels in the serum (a) and knee joint synovial fluid (b) of CIA mice and nonimmunized (NI) control mice ( $N=10$ mice per group). c Representative images of cellular zinc levels in the joint tissues of $\mathrm{CIA}$ and $\mathrm{NI}$ mice ( $\mathrm{N}=5$ mice per group). c, cartilage; $\mathrm{s}$, synovium. $\mathbf{d}$ Relative mRNA levels of ZIP family (zinc importer) and ZNT family (zinc exporter) members in total synovial cells were quantified by qRT-PCR analysis ( $N=6$ mice per group). The error bars represent $\pm S D$, and unpaired two-tailed Student's $t$-tests were performed to determine differences between groups (a-d). e Representative images of immunostaining for MMP3, ZIP8, MTF1, and MT1/MT2 in the synovium of CIA and NI mice ( $N=5$ mice per group). $\mathbf{f}$ Microarray analysis of the indicated ZIP family members in synovial tissues from patients with rheumatoid arthritis (RA; $N=33)$, patients with osteoarthritis (OA; $N=26)$, and healthy individuals (HE; $N=20)$. Microarray data were obtained from the Gene Expression Omnibus database at the National Center for Biotechnology Information (NCBI). The box indicates the 25th and 75th percentiles, with the centerline representing the mean; significance was analyzed by one-way ANOVA followed by Bonferroni's post hoc comparison. ${ }^{*} P<0.05 ;{ }^{* * *} P<0.005 ;{ }^{* * *} P<0.0005$; ns, not significant. Scale bars: $50 \mu \mathrm{m}$.

$M t f 1^{+/-}$and $M t 1^{-1-} M t 2^{-1-}$ mice exhibited less inhibition than Slc39a8 ${ }^{+/-}$mice (Fig. 2a). Similarly, the reductions in CIA severity (clinical score, Fig. 2b), paw thickness (Supplementary Fig. 1a, b), and type II collagenspecific autoantibody production (Fig. 2c) were notable and significant in Slc39a $8^{+/-}$mice, whereas $\mathrm{Mtf1}^{+/-}$and $M t 1^{-l-} M t 2^{-1-}$ mice exhibited reduced or nonsignificant inhibition of these CIA parameters.

Inflammatory arthritis (to which CIA is classified) is also characterized by synoviocyte proliferation with synovial hyperplasia, synovitis with immune cell infiltration, and angiogenesis in synovial tissues ${ }^{1,2,5}$. These hallmarks of CIA were also significantly inhibited in $S l c 39 a 8^{+/-}$mice and to a lesser degree in $M t f 1^{+-}$and $M t 1^{-1-} M t 2^{-1-}$ mice (Fig. 2d-f and Supplementary Fig. 1c, d). Pannus formation and its invasion into adjacent cartilage and bone are important steps in the erosion of cartilage and bone during RA pathogenesis. These processes are mediated by the actions of TRAP-positive osteoclasts, which are regulated by the expression of RANKL ${ }^{1,2,5}$. Consistent with this finding, under CIA conditions, Slc39a $8^{+/-}$mice exhibited significant reductions in pannus formation (Supplementary Fig. 2a), RANKL expression (Supplementary Fig. 2b), the differentiation of TRAP-positive osteoclasts in the pannus of the bone-cartilage interface (Supplementary Fig. 2c) and cartilage destruction (Supplementary Fig. 2d), whereas these CIA hallmarks were less apparent in $\mathrm{Mtfl}^{+/-}$and $M t 1^{-1-} M t 2^{-/-}$mice.

ZIP8 is predominantly expressed in infiltrated $\mathrm{CD}^{+} \mathrm{T}$ cells

Immunofluorescence analysis of the synovial tissues of CIA mice or primary total synovial cells isolated from these mice revealed that ZIP8 was upregulated in multiple cell types in CIA mice, including vimentin-positive FLSs, B220-positive B cells, CD4-positive T cells, and CD11bpositive macrophages (Fig. 3a, b). We also quantified the number of ZIP8-positive cells among the infiltrated immune cells in the synovial tissues of CIA mice. Flow cytometric analysis revealed that almost all $(99.8 \%) \mathrm{CD}^{+}$ $\mathrm{T}$ cells highly expressed ZIP8 on the cell surface, whereas less than half of $\mathrm{CD}_{11} \mathrm{~b}^{+}$macrophages and $\mathrm{B} 22 \mathrm{O}^{+} \mathrm{B}$ cells were positive for ZIP8 expression (Fig. 3c). Moreover, ZIP8 was highly upregulated in activated $\mathrm{CD} 4^{+} \mathrm{T}$ cells but not in activated $\mathrm{B} 220^{+} \mathrm{B}$ cells or $\mathrm{CD} 11 \mathrm{~b}^{+}$macrophages (Supplementary Fig. 3a-c). Based on the prevalent upregulation of ZIP8 in $\mathrm{CD} 4^{+} \mathrm{T}$ cells, we next focused on the role of zinc mobilization in $\mathrm{CD} 4^{+} \mathrm{T}$ cells during CIA pathogenesis.

\section{ZIP8 depletion in T cells inhibits CIA in mice}

To elucidate the function of ZIP8 in infiltrated CD4 ${ }^{+}$ $\mathrm{T}$ cells and $\mathrm{CD} 11 \mathrm{~b}^{+}$macrophages, we generated cell 


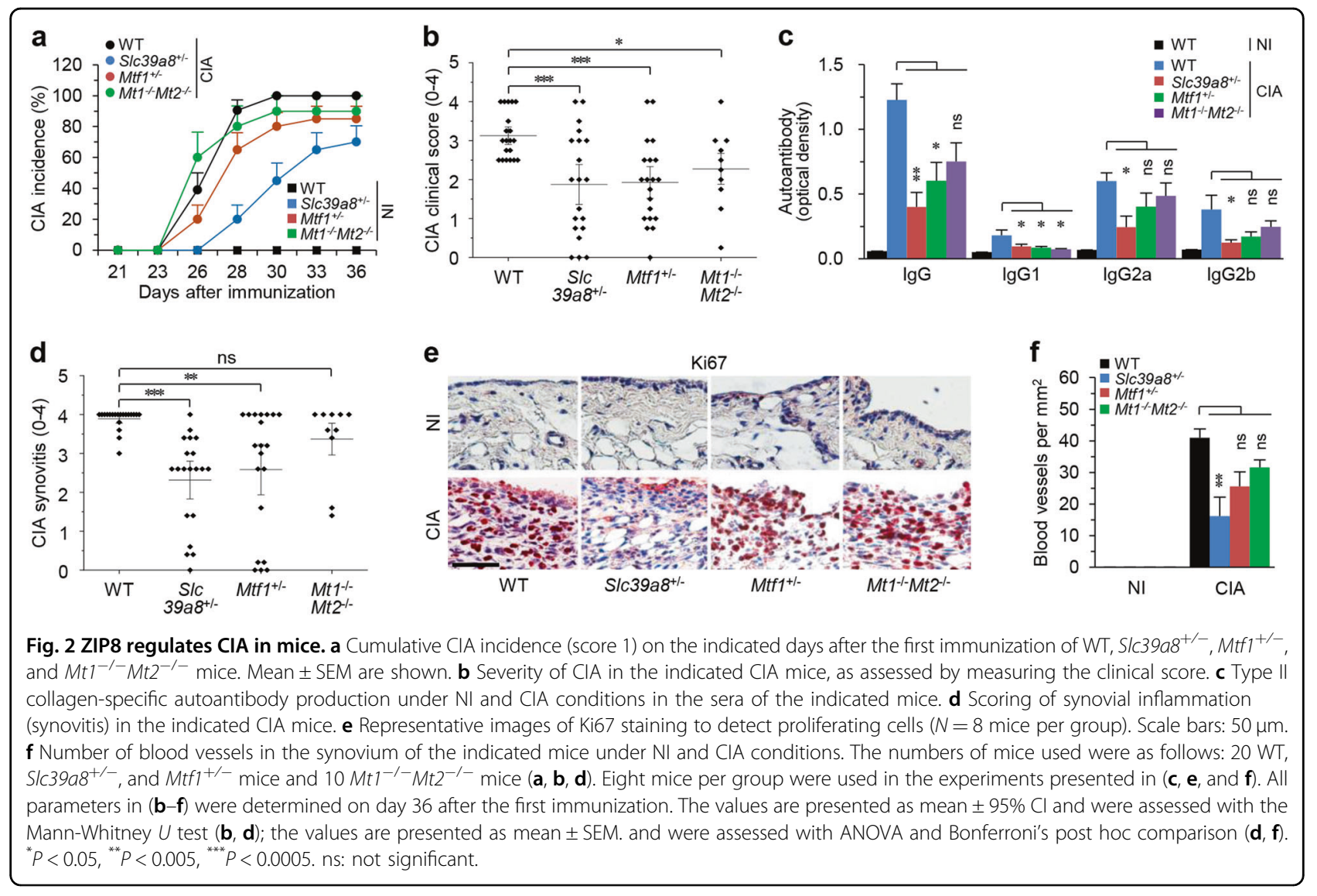

type-specific cKO mice: $S l c 39 a 8^{\mathrm{f} / \mathrm{f}} ; \mathrm{CD} 4-\mathrm{Cre}$ and $\mathrm{Slc39a} 8^{\mathrm{f} / \mathrm{f}}$; Lysm-Cre (Supplementary Fig. 4a). Slc39a ${ }^{\mathrm{f} / \mathrm{f}} ; \mathrm{CD} 4-\mathrm{Cre}$ mice exhibited striking reductions in CIA incidence, whereas less inhibition was observed in $\mathrm{Slc} 39 a 8^{\mathrm{f} / \mathrm{f}}$; Lysm-

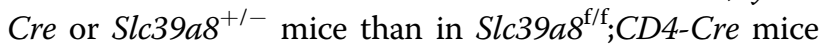
(Fig. 4a). Similarly, other CIA parameters were more markedly inhibited in Slc39a $8^{\mathrm{f} / \mathrm{f}} ; \mathrm{CD} 4-\mathrm{Cre}$ mice than in Slc39a ${ }^{\mathrm{f} / \mathrm{f}} ; \mathrm{Lysm}$-Cre or Slc39a $8^{+/-}$mice. These parameters included CIA severity (Fig. 4b), paw swelling (Supplementary Fig. 4b, c), synovial inflammation and hyperplasia (Fig. 4c, d and Supplementary Fig. 4d), the production of autoantibodies against type II collagen (Fig. 4e), angiogenesis in the inflamed synovial tissues (Fig. $4 \mathrm{f}$ and Supplementary Fig. 4e), pannus formation (Supplementary Fig. 5a), RANKL expression, the formation of TRAPpositive multinucleated osteoclasts in the pannus (Supplementary Fig. 5b, c), and cartilage destruction (Supplementary Fig. 5d). These results collectively indicate that the upregulation of ZIP8 in CD4 $4^{+} \mathrm{T}$ cells is crucial for the development of CIA in mice. We additionally observed normal development of $\mathrm{CD}^{+}{ }^{+} \mathrm{T}$ cells in Slc39a8 ${ }^{\mathrm{f} / \mathrm{f}} ; \mathrm{CD} 4$ Cre mice (Supplementary Fig. $6 \mathrm{a}-\mathrm{c}$ ), indicating that the inhibitory effects of T cell-specific ZIP8 depletion in CIA are not due to any alterations in $\mathrm{T}$ cell development.

\section{ZIP8 in $\mathrm{CD}^{+} \mathrm{T}$ cells regulates Th17 cell differentiation in $\mathrm{ClA}$ mice}

Compared with WT $\left(S l c 39 a 8^{\mathrm{f} / \mathrm{f}}\right)$ mice, ZIP8-deficient Slc39a ${ }^{\mathrm{fff}} ; C D 4-C r e$ mice exhibited significant decreases in the population of IL-17A-producing but not IFN- $\gamma$-producing $\mathrm{CD}^{+} \mathrm{T}$ cells in both the spleen (Fig. 5a) and lymph nodes (Fig. 5b) under CIA conditions. In addition, the numbers of $C D 4^{+} \mathrm{T}$ cells were decreased in the spleen and lymph nodes of $\operatorname{Slc} 39 a 8^{\mathrm{f} / \mathrm{f}} ; \mathrm{CD} 4-\mathrm{Cre}$ mice compared to WT mice under CIA conditions (Supplementary Fig. 7). Cytokine production in $\mathrm{CD} 4^{+} \mathrm{T}$ cells from Slc39as ${ }^{\mathrm{f} / \mathrm{f}}$ and Slc39a $8^{\mathrm{f} / \mathrm{f}} ; \mathrm{CD} 4-\mathrm{Cr}$ mice under CIA conditions was analyzed and revealed that ZIP8 deficiency was associated with significant reductions in IL-17A, TNF- $\alpha$, and IL-2 levels; increases in IL-10 production; and no significant changes in IFN- $\gamma$ and IL-6 (Fig. 5c, d). Moreover, the in vitro differentiation of Th17 but not Th1 cells was significantly inhibited by ZIP8 deficiency in Slc39a $8^{\mathrm{f} / \mathrm{f}}$; CD4-Cre mice (Fig. 5e). However, ZIP8 deficiency in Slc39a ${ }^{\mathrm{f} / \mathrm{f}} ; C D 4-C r e$ mice did not affect the regulatory $\mathrm{T}$ cell (Treg) population in CIA mice or Treg differentiation in vitro (Fig. 5f). In addition, the differentiation of Th2 cells was not significantly affected by ZIP8 deficiency (Supplementary Fig. 8). 
a

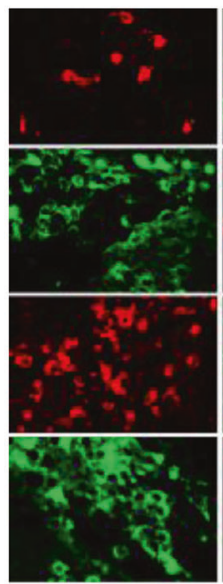

Markers
$\mathrm{ClA} /$ synovial tissue

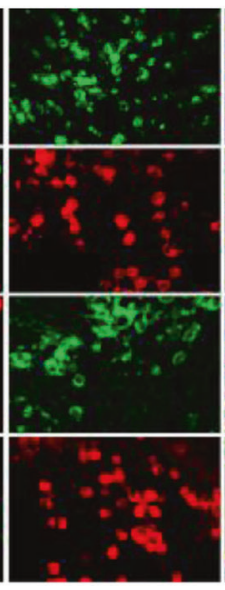

ZIP8

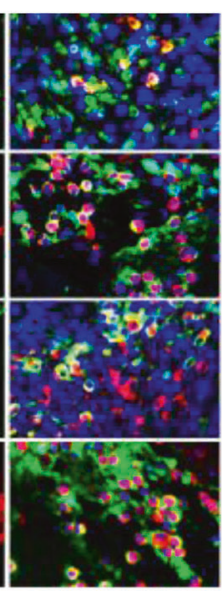

Merge/DAPI

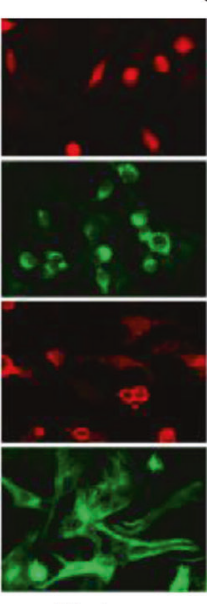

Markers
CIA/synovial cells

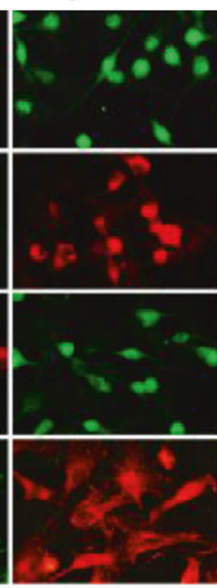

ZIP8

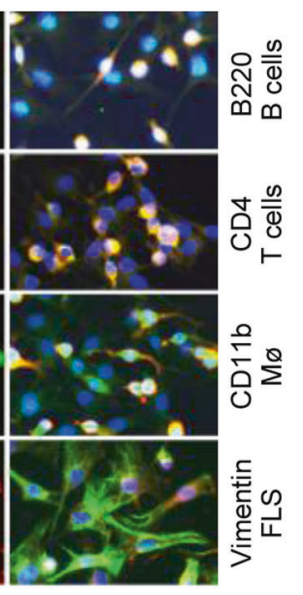

Merge/DAPI
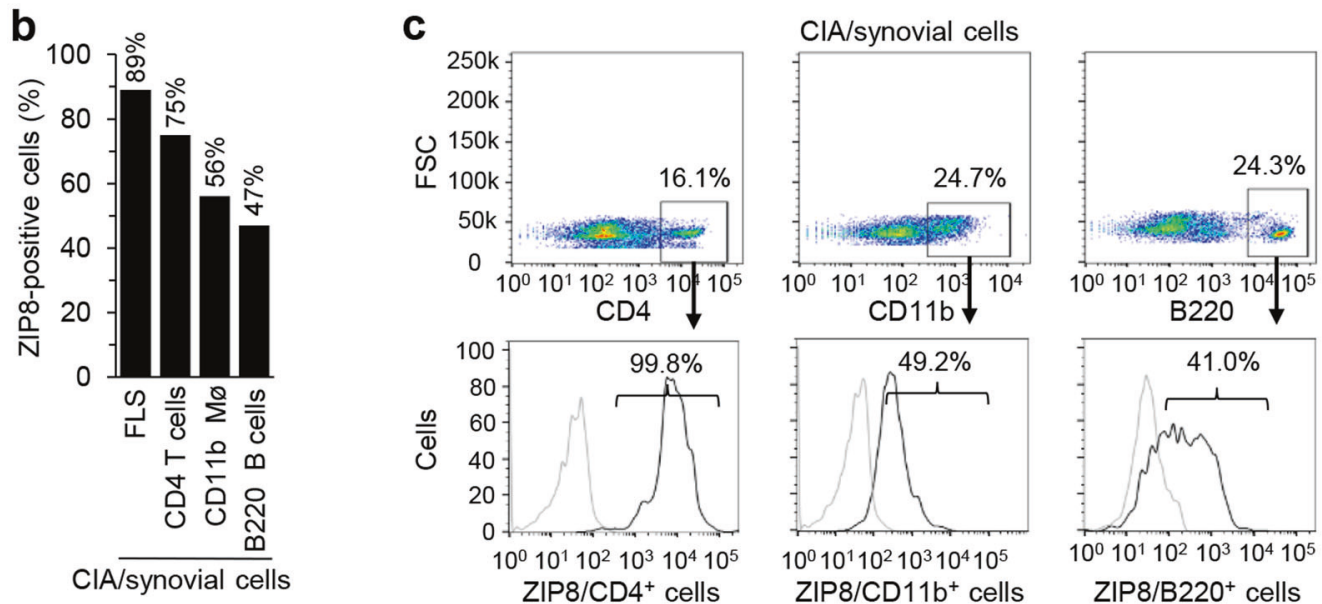

Fig. 3 Among the infiltrated immune cells, ZIP8 is predominantly expressed in CD4 ${ }^{+} \mathbf{T}$ cells. $\mathbf{a}$, $\mathbf{b}$ Typical immunofluorescence microscopic images of DAPI, ZIP8, and markers for B cells (B220), T cells (CD4), macrophages (CD11b), and fibroblast-like synoviocytes (FLSs, vimentin) in synovial tissues (left) and primary cultures of total synovial cells isolated from CIA mice (right) (a). The percentage of ZIP8-positive cells was determined by immunofluorescence microscopic analysis of primary cultures of total synovial cells isolated from CIA mice (b $N=5$ mice). $\mathbf{c}$ Flow cytometric analysis of ZIP8 expression on $\mathrm{CD}^{+}$cells, $\mathrm{CD} 11 \mathrm{~b}^{+}$cells, and $\mathrm{B}_{22} 2 \mathrm{O}^{+}$cells from total synovial cells isolated from the knee joints of CIA mice. The data shown in $(\mathbf{a}, \mathbf{c})$ are representative of five independent experiments.

ZIP8 is a key regulator of zinc influx in effector $\mathrm{CD}^{+}{ }^{+} \mathrm{T}$ cells

The activation of $\mathrm{CD}^{+}{ }^{+} \mathrm{T}$ cells from $\mathrm{C} 57 \mathrm{BL} / 6$ or DBA1/ $1 \mathrm{~J}$ background mice was associated with marked increases in ZIP8 mRNA and protein levels (Fig. 6a). However, we did not detect any increase in ZIP6 during $\mathrm{CD}^{+}{ }^{+} \mathrm{T}$ cell activation in our system (Supplementary Fig. 9a). The cell surface localization of ZIP8 on activated CD4 ${ }^{+} \mathrm{T}$ cells was confirmed by staining nonpermeabilized cells with an anti-ZIP8 antibody (Fig. 6b). We also observed increases in the total cellular level (Fig. 6c) and surface expression (Fig. 6d) of ZIP8 in Tem cells compared with Tnaive cells. Thus, ZIP8-mediated zinc influx may be an important regulatory mechanism for Tem cell activation. The role of ZIP8 in zinc influx was confirmed by measuring cellular zinc levels in Tem and Tnaive cells. Both cell types exhibited zinc influx after the addition of extracellular $\mathrm{ZnCl}_{2}$, and this influx was markedly inhibited by ZIP8 deficiency in Slc39a8 ${ }^{f / f}$;CD4-Cre mice (Fig. 6e). Furthermore, consistent with their increased expression of ZIP8, Tem cells exhibited more notable zinc influx than Tnaive cells, and this influx was dramatically inhibited by ZIP8 deficiency (Fig. 6e).

\section{ZIP8 primarily regulates effector $\mathrm{CD}^{+}{ }^{+} \mathrm{T}$ cell activation and proliferation through zinc flux}

Zinc is an essential component of TCR signaling during $\mathrm{T}$ cell activation ${ }^{35}$, and we examined the role of ZIP8 in TCR signaling. Whereas binding of Lck to CD4 was 


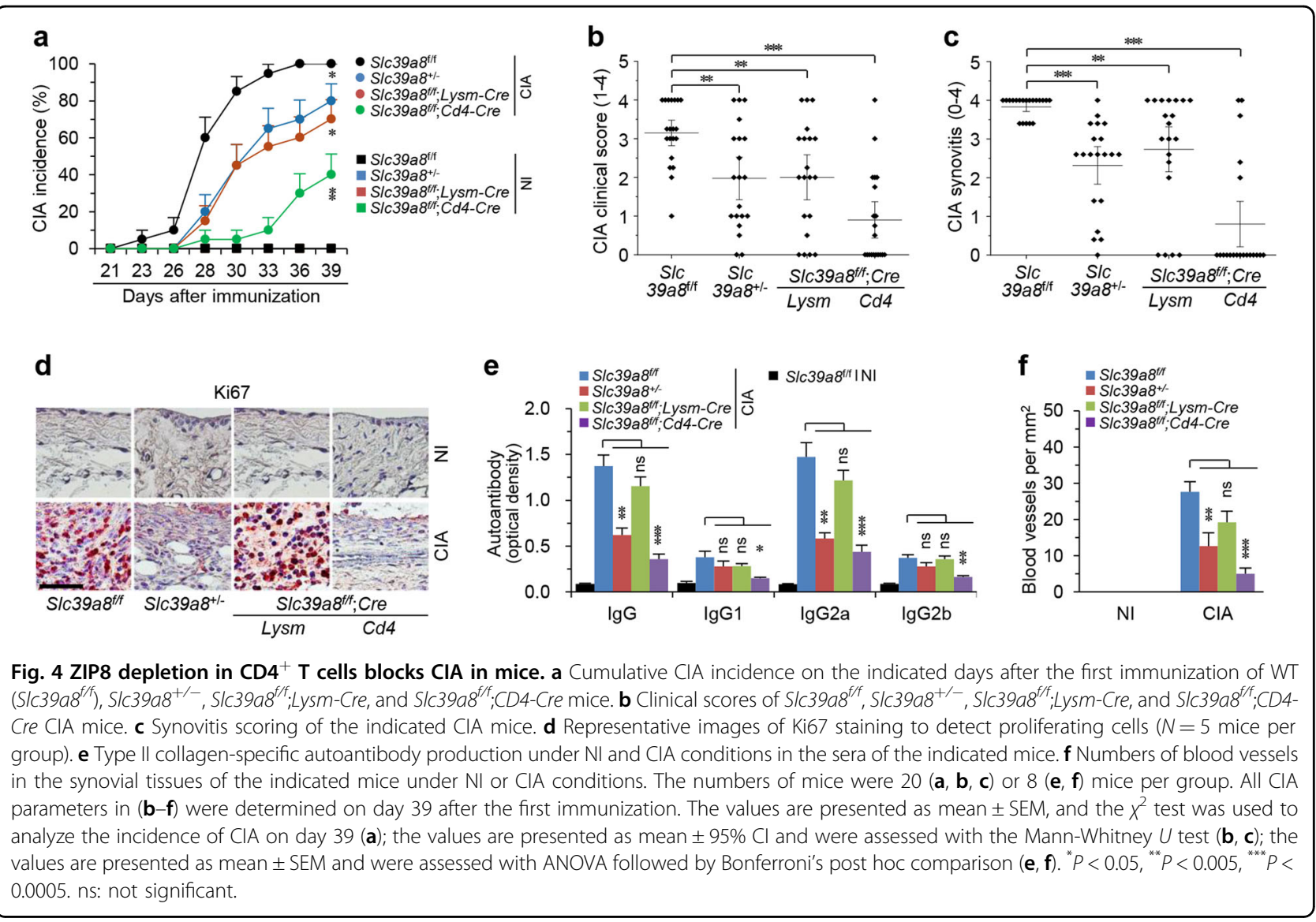

observed in ZIP8-expressing Tem and Tnaive cells, this binding was dramatically decreased in ZIP8-deficient Tem cells and slightly decreased in ZIP8-deficient Tnaive cells (Fig. 7a). ZIP8 deficiency was associated with decreases in the phosphorylation levels of TCR $\zeta$ and TCR component zeta chain of TCR-associated protein kinase 70 (Zap70) in both cell types, and a more profound decrease was seen in Tem cells than in Tnaive cells (Fig. 7b). However, the expression level of Shp-1, which is a negative regulator of TCR signaling, was not changed. ZIP8 deficiency also modulated the phosphorylation levels of ERK, JNK, and I $\mathrm{B} B \alpha$ and altered the degradation of IкB $\alpha$ in both Tem and Tnaive cells, with more marked effects observed in Tem cells than in Tnaive cells (Fig. 7c). Interestingly, ZIP8 deficiency did not affect AKT phosphorylation (Fig. 7c). As AKT is mainly involved in CD28-mediated signaling cascades $^{36}$, our results indicate that ZIP8 may have specific functions in TCR signaling but not in the CD28mediated signaling cascade. In addition to modulating TCR signaling, thymidine incorporation analysis revealed that ZIP8 deficiency significantly inhibited the proliferation of Tem and Tnaive cells, with more profound effects seen in Tem cells than in Tnaive cells (Fig. 7d). Similarly, cell division analysis by flow cytometry with CTV indicated that ZIP8 deficiency exerted more profound inhibitory effects on Tem cells than on Tnaive cells (Fig. 7e). We also found that depletion of extracellular zinc significantly inhibited the proliferation of activated $\mathrm{CD}^{+}{ }^{+} \mathrm{T}$ cells (Supplementary Fig. 9b, c). Therefore, ZIP8mediated zinc influx in Tem cells is important for activation and proliferation (Fig. 7f).

\section{Discussion}

Specific types of zinc transporters, such as ZNT and ZIP family members, exhibit differential effects on various immune cells. Therefore, the regulation of zinc mobilization by cell type-specific ZNTs or ZIPs may be linked to the development of inflammatory diseases ${ }^{19,20,22,23,37}$. However, it has not yet been elucidated whether cell typespecific and transporter-specific zinc mobilization are involved in RA pathogenesis. Here, we investigated whether RA pathogenesis was associated with zinc mobilization by a specific zinc transporter in specific subtypes of immune cells. The present study showed that, as in RA patients $^{38}$, zinc levels were locally increased in the synovial fluid and synovial tissues of CIA mice and that among all the examined zinc importers (ZIP1-ZIP14) and exporters (ZNT1-ZNT10), ZIP8 was specifically upregulated in the synovial tissues of inflamed joints in CIA mice and RA patients. We also demonstrated that ZIP8 was 


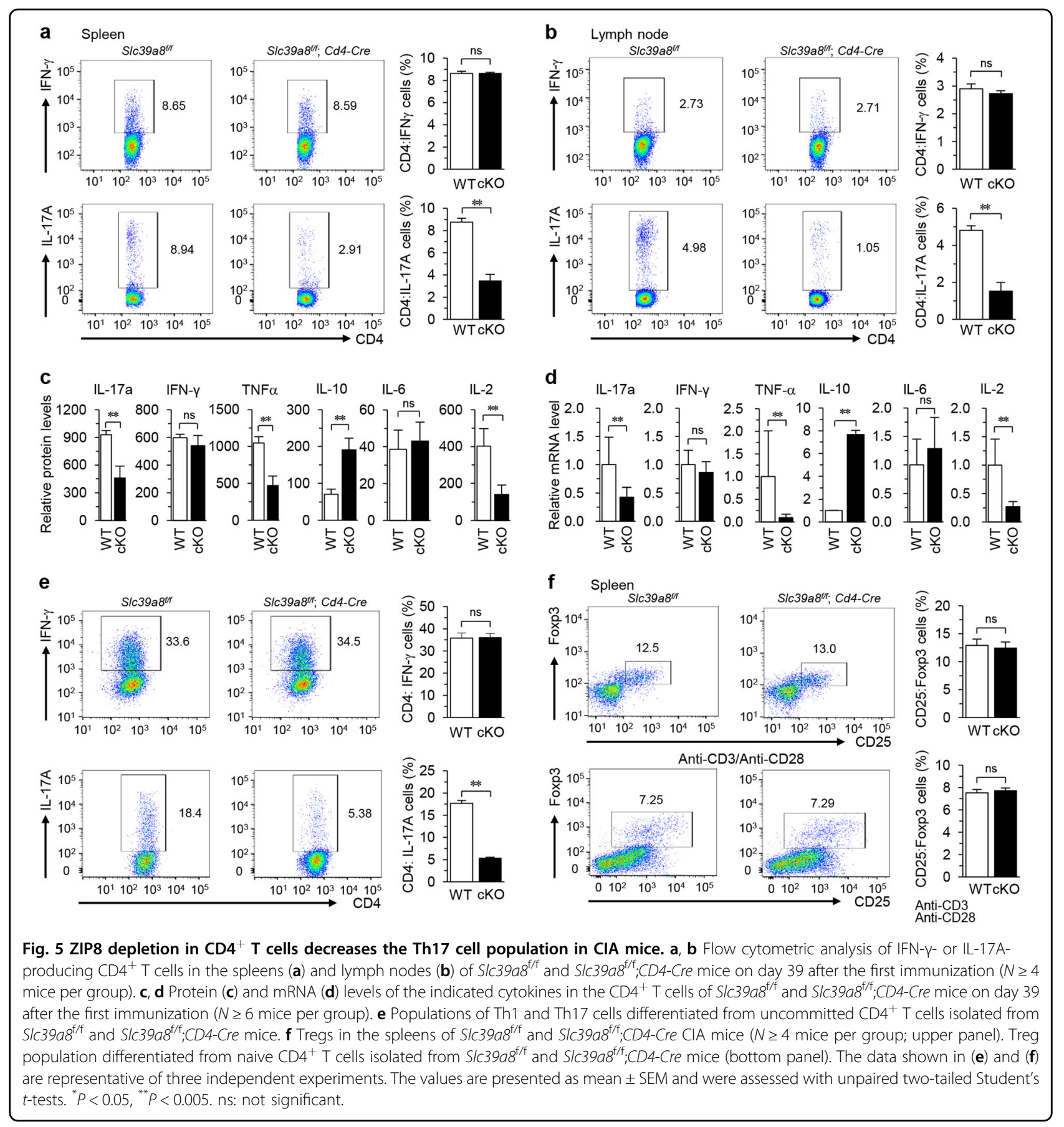

profoundly upregulated in infiltrated $\mathrm{CD} 4^{+} \mathrm{T}$ cells. Therefore, our current findings suggest that ZIP8mediated zinc influx in infiltrated $\mathrm{CD}^{+} \mathrm{T}$ cells contributes to the onset and progression of CIA.

In this report, we also examined whether the zinc-ZIP8-MTF1-MT axis regulates CIA pathogenesis using Slc39a8 $8^{+/-}, M t f 1^{+/-}$, and $M t 1^{-/-} M t 2^{-/-}$mice, as this axis is important in the pathogenesis of $\mathrm{OA}^{26}$. However, we found that $S l c 39 a 8^{+/-}$mice exhibited strong inhibition of CIA, whereas reduced inhibitory effects were seen in $\mathrm{Mtf1}^{+/-}$and $M t 1^{-/-} \mathrm{Mt2^{-/- }}$ mice, and these findings were at odds with the pathogenic mechanism of OA. Therefore, our results indicate differences in the etiology and pathogenesis of RA and OA even though both conditions are regulated by ZIP8-mediated zinc influx. Different zinc-induced signaling pathways are, therefore, likely to be involved in OA and RA. Based on a previous report and current data, we suggest that 

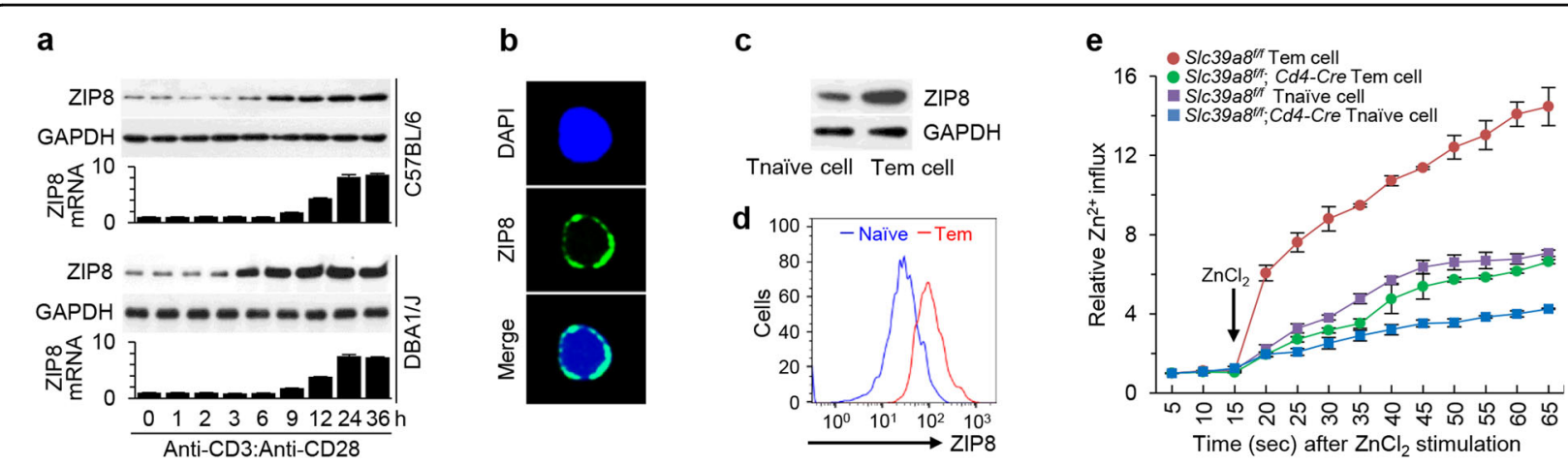

Fig. 6 ZIP8 is a key regulator of zinc influx in effector $\mathrm{CD}^{+} \mathbf{T}_{\text {T }}$ cells. a CD4 ${ }^{+}$T cells were isolated from WT mice (C57BL/6 and DBA/1 J) and stimulated with $5 \mathrm{\mu g} / \mathrm{mL}$ anti-CD3 and anti-CD28 antibodies. The mRNA and protein levels of ZIP8 were determined at the indicated time points. b Representative confocal microscopic images of ZIP8 in primary cultures of mouse CD4 ${ }^{+} T$ cells stimulated with anti-CD3 and anti-CD28 antibodies for 24 h. Nuclei were stained with 4,6-diamidino-2-phenylindole (DAPI). c, d Representative immunoblot image (c) and flow cytometric analysis (d) of ZIP8 in isolated CD4 ${ }^{+}$Tnaive and Tem cells. e Analysis of zinc influx in isolated Tnaive and Tem cells from S/C39a $8^{\mathrm{f} / \mathrm{f}}$ and S/C39a8 $8^{\mathrm{f} / \mathrm{f}} ; \mathrm{CD} 4-\mathrm{Cre}$ mice. The arrow indicates the time of $\mathrm{ZnCl}_{2}$ treatment $(45 \mu \mathrm{M})$. The data shown in $(\mathbf{a}-\mathbf{e})$ are representative of three independent experiments. The values are presented as mean $\pm \mathrm{SD} .{ }^{*} P<0.05,{ }^{* *} P<0.005$.

ZIP8-mediated zinc influx into chondrocytes is important for OA pathogenesis by upregulating matrix-degrading catabolic enzymes ${ }^{26,27}$, while ZIP8 mediated RA pathogenesis primarily by modulating the functions of $\mathrm{CD} 4^{+}$ $\mathrm{T}$ cells, such as Tem cell activation, including that of Th17 cells.

Our present results further demonstrate that ZIP8mediated zinc influx regulates Tem cell activation and proliferation. Moreover, we found that depletion of extracellular zinc abrogates the in vitro proliferation and activation of $\mathrm{CD} 4^{+} \mathrm{T}$ cells. This observation is consistent with a previous report that an influx of extracellular zinc regulates $\mathrm{CD}^{+}{ }^{+} \mathrm{T}$ cell activation ${ }^{23}$. ZIP8 appears to be an important zinc importer in $\mathrm{CD} 4^{+} \mathrm{T}$ cells that infiltrate inflamed joint tissues. Indeed, beyond our observation that ZIP8 was specifically upregulated in $\mathrm{CD} 4^{+} \mathrm{T}$ cells, we also found that the degree of zinc influx was proportional to the expression level of ZIP8 in these cells: ZIP8 expression was low in Tnaive cells, increased upon activation and was maintained at an elevated level in Tem cells. Consequently, more notable zinc influx was observed in Tem cells than in Tnaive cells, and the inhibitory effects of ZIP8 depletion on zinc influx were more profound in Tem cells than in Tnaive cells. Tem cells were larger than Tnaive cells. Thus, the increase in ZIP8 in Tem cells is essential for supplying zinc to maintain adequate zinc levels during the TCR signaling cascade. Therefore, we propose that ZIP8-mediated zinc influx in infiltrated $\mathrm{CD}^{+} \mathrm{T}$ cells is an important mechanism for regulating $\mathrm{CD}^{+} \mathrm{T}$ cell activation in the synovial region. We also found that ZIP8 deficiency significantly inhibited the differentiation of Th17 cells. Upon $\mathrm{CD} 4^{+} \mathrm{T}$ cell activation, ZIP8 expression levels were increased. Thus, during $\mathrm{CD}^{+} \mathrm{T}$ cell differentiation, ZIP8 depletion may inhibit Th17 cell differentiation by dysregulating TCR/ CD28 signaling because TCR signaling was weakened while CD28 signaling was intact. A previous report showed that increasing CD28 signaling inhibited Th17 cell differentiation ${ }^{39}$. Thus, ZIP8 preferentially influenced Th17 cell differentiation, while the differentiation of other Th cells was not significantly affected by ZIP8. In addition, because Th17 cell differentiation is crucial for RA pathogenesis, including RANKL upregulation ${ }^{1,2,5,40}$, it was unsurprising that CIA development was abrogated in $\mathrm{CD}^{+}{ }^{+} \mathrm{T}$ cell-specific cKO $\left(\mathrm{Slc} 39 a 8^{\mathrm{f} / \mathrm{f}} ; \mathrm{CD} 4-\mathrm{Cre}\right)$ mice. In addition, the total $\mathrm{CD} 4^{+} \mathrm{T}$ cell number was decreased in CIA-induced ZIP8-deficient mice, suggesting a role of ZIP8 in $\mathrm{CD}^{+} \mathrm{T}$ cell proliferation during CIA pathogenesis. Thus, our data suggest that ZIP8 expression in CD4 ${ }^{+}$ $\mathrm{T}$ cells regulates the TCR signaling cascade and $\mathrm{CD} 4^{+} \mathrm{T}$ cell differentiation and proliferation during RA development and pathogenesis. However, it has also been reported that zinc supplementation inhibits Th17 cell differentiation ${ }^{41}$. Therefore, this finding suggests that the differentiation and function of Th17 cells can be inhibited at excessive or insufficient zinc concentrations. Thus, in addition to zinc supplementation, our data indicate that inhibiting certain zinc transporters may be another strategy for treating RA.

Zinc is an essential element for innate and adaptive immune responses ${ }^{18}$. Therefore, the elucidation of the roles of specific zinc transporters in immune cell functions could help us understand the molecular mechanisms underlying inflammatory diseases. Here, we provide evidence that inflammatory autoimmune diseases (i.e., RA) can be regulated by cell type- and transporter-specific zinc mobilization. Conclusively, ZIP8 is specifically upregulated in $\mathrm{CD}_{4}^{+} \mathrm{T}$ cells that infiltrate the inflamed synovial 


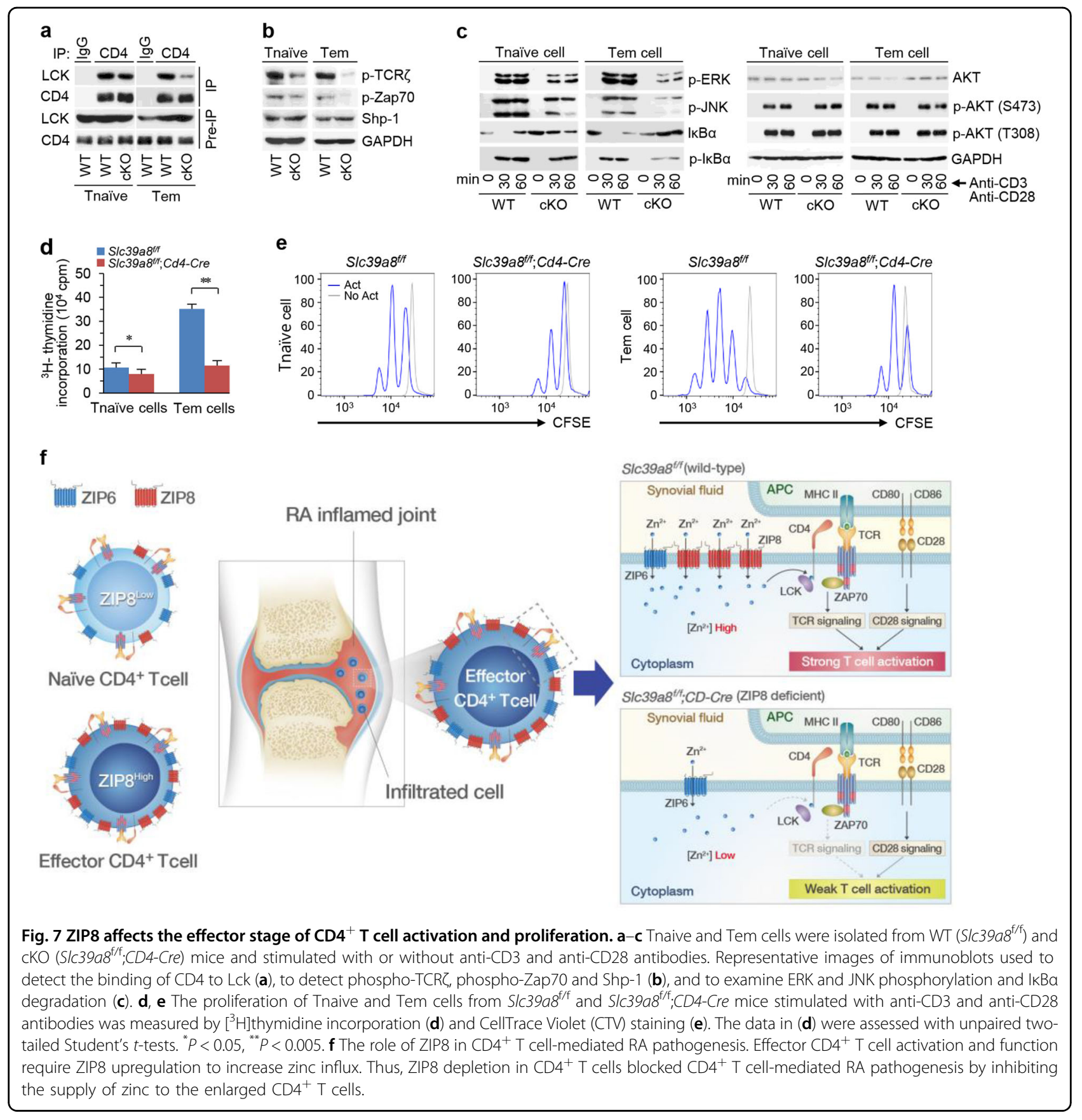

tissues of CIA joints and crucially contributes to CIA pathogenesis by regulating the activation and proliferation of effector $\mathrm{CD}_{4}^{+} \mathrm{T}$ cells, including Th17 cells. Our results collectively suggest that ZIP8 is a candidate therapeutic target for treating RA.

\section{Acknowledgements}

This work was supported by a grant to J.S.C. and S.G.P. from the National Research Foundation of Korea (2016R1A5A1007318). J.S.C. was additionally supported by grants from the National Research Foundation of Korea (2016R1A3B1906090 and 2019RM3A9A8065758) and the Korea Health Industry
Development Institute (H114C3484). S.G.P. was also supported by grants from the National Research Foundation of Korea (2017R1E1A1A01074299 and 2016M3C7A1905475) and by a grant from the Research of Korea Centers for Disease Control and Prevention (2020-ER6902-00).

\section{Author details}

${ }^{1}$ School of Life Sciences, Gwangju Institute of Science and Technology, Gwangju 61005, Republic of Korea. ${ }^{2}$ Cell Logistics Research Center, Gwangju Institute of Science and Technology, Gwangju 61005, Republic of Korea.

${ }^{3}$ Infectious Disease Research Center, Korea Research Institute of Bioscience \& Biotechnology (KRIBB), Daejeon 34141, Republic of Korea. ${ }^{4}$ National Creative Research Initiatives Center for Osteoarthritis Pathogenesis, Gwangju Institute of 
Science and Technology, Gwangju 61005, Republic of Korea. ${ }^{5}$ College of Pharmacy, Seoul National University, Seoul 08826, Republic of Korea

\section{Author contributions}

J.K., J.S.K., and S.H.P.: Study design, data acquisition, analysis and interpretation, and writing the original draft. K.Y.S., S.K.K., Y.S., I.J.J., and J.I.Y.: Experiments. J.S.C. and S.G.P.: Taking responsibility for the integrity of this work.

\section{Conflict of interest}

The authors declare no competing interests.

\section{Publisher's note}

Springer Nature remains neutral with regard to jurisdictional claims in published maps and institutional affiliations.

Supplementary information The online version contains supplementary material available at https://doi.org/10.1038/s12276-021-00591-1.

Received: 27 October 2020 Revised: 20 December 2020 Accepted: 8 January 2021.

Published online: 1 April 2021

\section{References}

1. Mclnnes, I. B. \& Schett, G. The pathogenesis of rheumatoid arthritis. N. Engl. J. Med. 365, 2205-2219 (2011).

2. Nevius, E., Gomes, A. C. \& Pereira, J. P. Inflammatory cell migration in rheumatoid arthritis: a comprehensive review. Clin. Rev. Allergy Immunol. 51, 59-78 (2016).

3. Karami, J., Aslani, S., Jamshidi, A., Garshasbi, M. \& Mahmoudi, M. Genetic implications in the pathogenesis of rheumatoid arthritis; an updated review. Gene 702, 8-16 (2019).

4. Okada, Y., Eyre, S., Suzuki, A., Kochi, Y. \& Yamamoto, K. Genetics of rheumatoid arthritis: 2018 status. Ann. Rheum. Dis. 78, 446-453 (2019).

5. Mclnnes, I. B. \& Schett, G. Cytokines in the pathogenesis of rheumatoid arthritis. Nat. Rev. Immunol. 7, 429-442 (2007).

6. Alzabin, S. \& Williams, R. O. Effector T cells in rheumatoid arthritis: lessons from animal models. FEBS Lett. 585, 3649-3659 (2011).

7. Ehinger, M. et al. Influence of CD4 or CD8 deficiency on collagen-induced arthritis. Immunology 103, 291-300 (2001).

8. Kremer, J. M. et al. Treatment of rheumatoid arthritis with the selective costimulation modulator abatacept: twelve-month results of a phase iib, doubleblind, randomized, placebo-controlled trial. Arthritis Rheum. 52, 2263-2271 (2005).

9. Schiff, M. Abatacept treatment for rheumatoid arthritis. Rheumatology (Oxford) 50, 437-449 (2011).

10. Harrington, L. E. et al. Interleukin 17-producing CD4+ effector T cells develop via a lineage distinct from the T helper type 1 and 2 lineages. Nat. Immunol. 6, 1123-1132 (2005).

11. Park, H. et al. A distinct lineage of CD4 T cells regulates tissue inflammation by producing interleukin 17. Nat. Immunol. 6, 1133-1141 (2005).

12. Murphy, C. A. et al. Divergent pro- and antiinflammatory roles for IL-23 and IL12 in joint autoimmune inflammation. J. Exp. Med. 198, 1951-1957 (2003).

13. Lonergan, Z. R. \& Skaar, E. P. Nutrient zinc at the host-pathogen interface. Trends Biochem. Sci. 44, 1041-1056 (2019).

14. Fukada, T. \& Kambe, T. Molecular and genetic features of zinc transporters in physiology and pathogenesis. Metallomics 3, 662-674 (2011).

15. Mierzecki, A., Strecker, D. \& Radomska, K. A pilot study on zinc levels in patients with rheumatoid arthritis. Biol. Trace Elem. Res. 143, 854-862 (2011).

16. Zoli, A. et al. Serum zinc and copper in active rheumatoid arthritis: correlation with interleukin 1 beta and tumour necrosis factor alpha. Clin. Rheumatol. 17, 378-382 (1998).

17. Gammoh, N.Z. \& Rink, L. Zinc in infection and inflammation.Nutrients 9, 624 (2017).
18. Hojyo, S. \& Fukada, T. Roles of zinc signaling in the immune system. J. Immunol. Res. 2016, 6762343 (2016).

19. Liu, M. J. et al. ZIP8 regulates host defense through zinc-mediated inhibition of NF-kappaB. Cell Rep. 3, 386-400 (2013).

20. Gao, H. et al. Metal transporter Slc39a10 regulates susceptibility to inflammatory stimuli by controlling macrophage survival. Proc. Natl Acad. Sci. USA 114, 12940-12945 (2017).

21. Taniguchi, M. et al. Essential role of the zinc transporter ZIP9/SLC39A9 in regulating the activations of Akt and Erk in B-cell receptor signaling pathway in DT40 cells. PLOS ONE 8, e58022 (2013).

22. Miyai, T. et al. Zinc transporter SLC39A10/ZIP10 facilitates antiapoptotic signaling during early B-cell development. Proc. Natl Acad. Sci. USA 111, 11780-11785 (2014).

23. Yu, M. et al. Regulation of $\mathrm{T}$ cell receptor signaling by activation-induced zinc influx. J. Exp. Med. 208, 775-785 (2011).

24. Aydemir, T. B., Liuzzi, J. P., McClellan, S. \& Cousins, R. J. Zinc transporter ZIP8 (SLC39A8) and zinc influence IFN-gamma expression in activated human T cells. J. Leukoc. Biol. 86, 337-348 (2009).

25. Palmer, L. D. \& Skaar, E. P. Transition metals and virulence in bacteria. Annu. Rev. Genet. 50, 67-91 (2016).

26. Kim, J. H. et al. Regulation of the catabolic cascade in osteoarthritis by the zincZIP8-MTF1 axis. Cell 156, 730-743 (2014).

27. Won, $Y$. et al. Pleiotropic roles of metallothioneins as regulators of chondrocyte apoptosis and catabolic and anabolic pathways during osteoarthritis pathogenesis. Ann. Rheum. Dis. 75, 2045-2052 (2016).

28. Brand, D. D., Latham, K. A. \& Rosloniec, E. F. Collagen-induced arthritis. Nat. Protoc. 2, 1269-1275 (2007).

29. Park, S. H. et al. BATF regulates collagen-induced arthritis by regulating $T$ helper cell differentiation. Arthritis Res. Ther. 20, 161 (2018).

30. Seifer, D. R. et al. Novel synovial fluid recovery method allows for quantification of a marker of arthritis in mice. Osteoarthr. Cartil. 16, 1532-1538 (2008).

31. Woetzel, D. et al. Identification of rheumatoid arthritis and osteoarthritis patients by transcriptome-based rule set generation. Arthritis Res. Ther. 16, R84 (2014).

32. Waldron, K. J., Rutherford, J. C., Ford, D. \& Robinson, N. J. Metalloproteins and metal sensing. Nature 460, 823-830 (2009).

33. Galvez-Peralta, M. et al. ZIP8 zinc transporter: indispensable role for both multiple-organ organogenesis and hematopoiesis in utero. PLOS ONE 7, e36055 (2012).

34. Gunes, C. et al. Embryonic lethality and liver degeneration in mice lacking the metal-responsive transcriptional activator MTF-1. EMBO J. 17, 2846-2854 (1998).

35. Lin, R. S., Rodriguez, C., Veillette, A. \& Lodish, H. F. Zinc is essential for binding of p56(lck) to CD4 and CD8alpha. J. Biol. Chem. 273, 32878-32882 (1998).

36. Park, S. G. et al. The kinase PDK1 integrates T cell antigen receptor and CD28 coreceptor signaling to induce NF-kappaB and activate T cells. Nat. Immunol. 10, 158-166 (2009)

37. Hojyo, S. et al. Zinc transporter SLC39A10/ZIP10 controls humoral immunity by modulating B-cell receptor signal strength. Proc. Natl Acad. Sci. USA 111, 11786-11791 (2014).

38. Silverio Amancio, O. M., Alves Chaud, D. M., Yanaguibashi, G. \& Esteves Hilario, M. O. Copper and zinc intake and serum levels in patients with juvenile rheumatoid arthritis. Eur. J. Clin. Nutr. 57, 706-712 (2003).

39. Bouguermouh, S., Fortin, G., Baba, N., Rubio, M. \& Sarfati, M. CD28 costimulation down regulates Th17 development. PLOS ONE 4, e5087 (2009).

40. Kim, K. W., Kim, H. R., Kim, B. M., Cho, M. L. \& Lee, S. H. Th17 cytokines regulate osteoclastogenesis in rheumatoid arthritis. Am. J. Pathol. 185, 3011-3024 (2015).

41. Kitabayashi, C. et al. Zinc suppresses Th17 development via inhibition of STAT3 activation. Int. Immunol. 22, 375-386 (2010). 